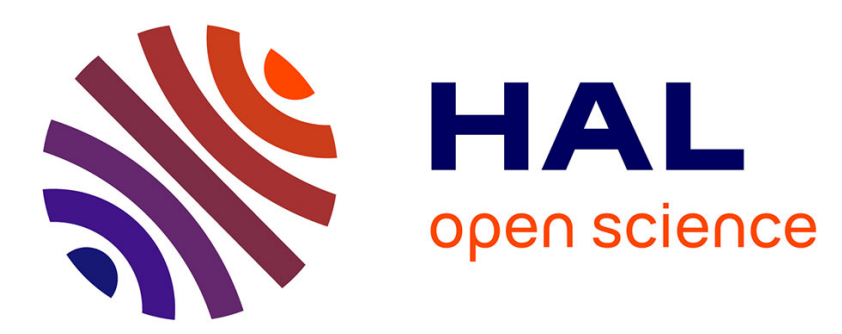

\title{
The emotional component in perceived quality of noises produced by car engines
}

Valery N. Nosulenko, Etienne Parizet, E. Samoylenko

\section{To cite this version:}

Valery N. Nosulenko, Etienne Parizet, E. Samoylenko. The emotional component in perceived quality of noises produced by car engines. International Journal of Vehicle Noise and Vibration, 2013, 9 (1-2), pp.96-108. hal-00957758

\section{HAL Id: hal-00957758 \\ https://hal.science/hal-00957758}

Submitted on 11 Mar 2014

HAL is a multi-disciplinary open access archive for the deposit and dissemination of scientific research documents, whether they are published or not. The documents may come from teaching and research institutions in France or abroad, or from public or private research centers.
L'archive ouverte pluridisciplinaire HAL, est destinée au dépôt et à la diffusion de documents scientifiques de niveau recherche, publiés ou non, émanant des établissements d'enseignement et de recherche français ou étrangers, des laboratoires publics ou privés. 


\title{
The emotional component in perceived quality of noises produced by car engines
}

\author{
Valery Nosulenko* \\ Institute of Psychology, \\ Russian Academy of Sciences, \\ 13, Yaroslavskaya Str., 129366, Moscow, Russia \\ E-mail: valery.nosulenko@gmail.com \\ *Corresponding author
}

\section{Etienne Parizet}

Laboratoire Vibrations Acoustique LVA,

INSA-Lyon, F-69621, France

E-mail: etienne.parizet@insa-lyon.fr

\section{Elena Samoylenko}

Institute of Psychology,

Russian Academy of Sciences,

13, Yaroslavskaya Str., 129366, Moscow, Russia

E-mail: elena.samoylenko@gmail.com

\begin{abstract}
This study dealt with evaluation and paired comparison of noises of seven diesel cars running at idle. Participants evaluated noises' difference, indicated which one was the most appreciable, and verbally compared them when explaining the reasons of their choice. A systems method of analysis of free verbalisations allowed to quantitatively analyse the set of characteristics which are the most significant for the choice of the more pleasant sound. The results showed that emotional component was significantly present in the set of verbal characteristics of the noises' perceived quality and the 'weight' of this component in the set of evaluative characteristics was different for males and females as well as for participants with different experience of driving the investigated cars. The proposed verbal protocol analysis can be used by the supplier to evaluate influence of car noises and to identify the part of emotive attributes in their perceived quality.
\end{abstract}

Keywords: verbalisations; in-cars noise; perceived quality; emotions; preferences.

Reference to this paper should be made as follows: Nosulenko, V., Parizet, E. and Samoylenko, E. (2013) 'The emotional component in perceived quality of noises produced by car engines', Int. J. Vehicle Noise and Vibration, Vol. 9, Nos. 1/2, pp.96-108.

Biographical notes: Valery Nosulenko graduated from the Institute of Electronics, Moscow and in 1980 obtained a PhD in Psychology at the USSR Academy of Sciences, on the topic of sounds' evaluation in communicative situations. He is a Senior Researcher in the Institute of Psychology, Russian 
Academy of Sciences, and responsible for the laboratory Communication in the Augmented Environment in the Center of Experimental Psychology (Moscow City Psycho-pedagogical University). For over 25 years he has worked in different French-Russian scientific and applied projects. His scientific interest is focused on perception of complex objects and evaluation of their perceived quality. $\mathrm{He}$ is co-responsible for the international research programme Cognition and Communication, and a member of the scientific committee for the Cognitive Technologies programme (EDF, MSH Foundation, Paris).

Etienne Parizet, after graduating from Ecole Polytechnique (Palaiseau, France), obtained his PhD in Acoustics at the Université du Maine, France, on the topic of speech intelligibility in cars. He has worked for over 12 years for Renault, mainly on the theme of applied psychoacoustics. He also managed the acoustic team of the research centre. In 2000, he joined the Vibration and Acoustic Laboratory of INSA Lyon to develop the activity of this laboratory as regards to acoustic perception. His work is mainly focused on sound perception (investigation on listening test experiments), vibratory comfort and interactions between acoustic and vibratory modalities in a complex situation.

Elena Samoylenko graduated from the Lomonosov University, Moscow, Russia and in 1986 he obtained his PhD in Psychology at the USSR Academy of Sciences, on the topic of comparison in the cognitive-communicative situations. She is a Senior Researcher in the Institute of Psychology, Russian Academy of Sciences, and in the Center of Experimental Psychology (Moscow City Psycho-pedagogical University). From 1986, she takes part in the Russian-French studies under the auspice of the Foundation House of Human Sciences (FMSH) as a co-responsible for the programme Cognition and Communication. She elaborated the method of free verbalisations' analysis that was applied in a number of research studies and namely in the Laboratory of the Cognitive Design (EDF R\&D) where she was a co-responsible for the programme of analysis of activity in augmented environments.

\section{Introduction}

The goal of this study is to investigate perceived quality and preferences of noises produced by cars at idle. Emotional attitude to an object is one of the important components of its perceived quality. This attitude determines to a large extent the choice of preferences (Bradley and Lang, 2000; Parker et al., 2008; Västfjäll et al., 2002). One of the ways to get information about emotional components of perception concerns analysis of verbal descriptions of perceived objects (Scherer, 2005).

In this study, an original method of analysis of free verbalisations (Nosulenko and Samoylenko, 1997, 2001; Samoylenko et al., 1996) is used to identify those characteristics of objects being compared that are perceived as the most significant ones (objects' perceived quality) as well as to evaluate the 'weight' of important categories of characteristics and in particular of the emotional ones. The analysis of free verbalisations shows peculiarities of positive or negative emotional attitude to objects and reveals the content of their perceived quality. As it was shown previously, such an analysis allows to interpret the criteria of choice of preferences as well as other data obtained in psychophysical studies (i.e., the perceptual space computed from similarity ratings). 
Moreover, the verbal portraits can be used to explain the perceptual space (Faure et al., 1996; Parizet et al., 2007).

The method is based on the principle that verbalisation produced when comparing objects can be used to identify the important aspects of their subjective representations. The verbal comparison is considered to be the key point in the procedure.

The effectiveness of this method has already been demonstrated in the studies dealing with musical timbres (Samoylenko et al., 1996), with diesel engine sounds (Nosulenko et al., 1998, 2000; Parizet and Nosulenko, 1999), car door closing sounds (Parizet et al., 2008), sounds and vibrations in cars at idle (Parizet et al., 2007), perception of delivery truck noise (Geissner, 2006) and with the sound of tapping on the dashboard in a car (Montignies, 2009; Montignies et al., 2010). The method has been also used in studies of human activities (Clouet, 2005; Lahlou et al., 2012; Le Bellu, 2011; Nosulenko, 2008; Nosulenko and Samoylenko, 2009). Our scheme of verbal data analysis has been applied successfully by Berg and Rumsey (2000) to study the correlation between emotive, descriptive and naturalness attributes of reproduced sounds.

This scheme for analysing verbal data was described in detail in Samoylenko et al. (1996). Each verbal text, produced by a subject when comparing a pair of sounds, is considered at three main levels of analysis:

1 The logical sense of verbal units: identification and coding of the verbal units, containing descriptions of similarities or differences between the stimuli; separation of verbal units into the ones corresponding to general parameters of comparison and the ones expressing concrete peculiarities; identification of verbal units according the way they are used to oppose the stimuli (classificational or gradual).

2 The sound-relatedness of verbal units: verbal units are labelled according to whether they are used to describe the global aspects or the specific properties of the sound (spatial, temporal, intensity, or spectral).

3 The semantic aspects of verbal units: classification of the lexical means used for characterising each of the compared sounds. The verbal units are first divided into those having descriptive features (dfe) ('loud', 'intense', etc.) or attitudinal features (afe) by means of which a person expresses an emotional or evaluative attitude to perceived sounds ('too aggressive ...', etc.). The group of descriptions expressing emotional-evaluative attitudes (afe) to perceived sounds is divided first into those containing information about emotional (emv) relations to sounds ('pleasant sound') and those where an aspect of artificiality or naturalness (ntl) of a sound is mentioned ('it is very far from natural'). Then, the (emv) units are divided into those describing positive and negative aspects (e.g., 'pleasant sound' and 'rather violent sound' coded as (pos) and (neg), respectively).

In our previous research, in which participants had to compare noises inside the diesel cars at idle, subjectively significant features used to distinguish the perceived car noises and to interpret the individual preferences were revealed (Nosulenko et al., 1998, 2000). The analysis concerned primarily the logical sense of verbalisations and the soundrelatedness of verbal units. As for the semantic aspects, only the results concerning the descriptive attributes of sounds ('loud', 'soft', 'high', 'low', 'fast', 'slow', 'regular', 'sharp', 'vibrating', etc.) were presented.

The focus of the present article is on the analysis of the emotive components of verbalisations associated with the choice of the cars' preferences. 


\section{Experiment}

\subsection{Stimuli}

For the present study, recordings were made in seven diesel engine cars. An acoustic mannequin was placed in the driver position to record the noise of engine running at idle in a realistic way. From these recordings, seven 5 seconds samples were prepared. Presentations were made through electrostatic headphones in a quiet room. The noise level of the samples was not modified from the recorded noise.

\subsection{Subjects}

Seventy one subjects participated in the experiment (49 males and 22 females). Ten of them were experts in evaluation of car engines' noises ('professionals') and nine were not specialists ('naive'). The other 52 subjects being the drivers of the cars used as the experimental stimuli were divided into seven equal in number groups on the basis of the type of the car they had experience of driving.

\subsection{Procedure}

The seven noises were presented in pairs according to the Ross (1939) series, after a preliminary random arrangement, ensuring that each subject was submitted to a different series. Two pairs were added at the beginning of the experiment for training, giving a total number of 23 pairs. All possible pairs of different cars (21 pairs, plus two learning pairs) were presented to subjects in a randomised order. Each stimulus pair could be repeated if requested by the subject.

The subjects were asked to imagine themselves as seated in a real car running at idle. Their task was to compare a pair of noises and to select the preferred one (tie answers were allowed).

For each stimulus pair, the subjects had to:

- $\quad$ indicate the preferable noise

- $\quad$ evaluate the difference between the noises using the 8 -point scale $(0$ - no difference, 7 - very different)

- $\quad$ explain in a free form their answers.

Free verbalisations were tape recorded and transcribed verbatim.

\subsection{Verbal data analysis method}

Verbalisations produced by subjects were analysed according to the scheme described above. The first step consisted of separating the meaningful verbal units (e.g., 'the first car is the most noisy'). These verbal units were entered into a database along with other information (e.g., the subject's number, the stimulus pair for which the verbal unit was produced, etc.). As a result, a table of more than 10,000 lines was created. The next step of the analysis refined the coding of the verbal units according to the scheme of analysis (Samoylenko et al., 1996). 
The number of verbal units produced by subjects was found to vary from 81 to 258 , the average value being 149. The number of verbal units coded as emotive attributes varied from 5 to 66 , the average value being 28 (19\% of general verbal product). An average number of emotive attributes identified in professionals (26.3) was non-significantly smaller than in those identified in naïve ones (30), while an equal number of emotive attributes was identified in verbalisations produced by males and females (27.2 and 28, correspondingly).

Thereafter, when comparing the relative use of the different descriptive categories, the rate of occurrences of a given category $(\mathrm{Ni})$ was normalised with respect to the total number of verbal units produced by each subject within each subject group:

$$
N i_{\text {norm }}=N i * K p_{s}
$$

A rate coefficient $\left(K p_{s}\right)$ was calculated with respect to the average $\left(N_{a v}\right)$ of verbal units produced by group of subjects. The coefficient for a given subject $s$ was calculated as the ratio between $N_{a v}$ and the total number of verbal units, $N_{s}$, that the given subject produced:

$$
K p_{s}=N_{a v} / N_{s}
$$

All data on the frequency of use of verbal units will be presented in term of this normalised coefficient, both for computation based on the integral data for each subject and for verbal units in a single category of the database for a given subject.

The last step of the free verbalisation analysis consisted of grouping together verbal units that were thought to refer to the same characteristics of the sounds. The procedure is to calculate the normalised frequencies of use of this verbal unit in different situations of verbal comparison and to compare the result with other type of data (preferences and numerical evaluations of differences).

Here are the examples of verbal units expressing the positive aspects of emotive attitudes to this or that described sound (emv-pos): 'more pleasant', 'very comfortable', 'reassuring', 'not aggressive', 'not embarrassing', 'supportable', 'more sympathetic', 'inspires more confidence', 'interesting', 'not too painful to hear', 'does not disturb', 'really honey', 'not violating', 'much appreciated', 'I like it', etc.

The examples of verbal units expressing the negative aspects of emotive attitude to the described sound (emv-neg): 'disaster', 'a real trash', 'a horror', 'arduous', 'disagreeable', 'unpleasant', 'annoying', 'disgusting', 'is really a headache', 'terrible', 'it irritates me', 'quite intolerable', 'unsatisfactory', 'not the pink side', 'atrocious', 'infernal', 'makes me sick at heart', 'awful', 'hateful', etc.

The final numerical descriptors were the 'verbal portraits' of the cars. For each car and each of the feature categories, the number of positive and negative occurrences was counted.

In order to compare the data, we counted the value of feature amplitude $F i$ ( $i$ denoting one of the seven sets of stimuli) that was defined in terms of the mean frequency of use of the 'positive' verbal units $F i_{p o s}$ (e.g., 'the sound inspires more confidence') and the mean frequency of use of the 'negative' verbal units $F i_{\text {neg }}$ (e.g., 'makes me sick at heart'):

$$
F i=\left|k_{p i}\right| *\left(F i_{\text {pos }}-F i_{\text {neg }}\right)
$$

where $k_{p i}$ is defined as: 


$$
k_{p i}=\left(F i_{\text {pos }}-F i_{\text {neg }}\right) /\left(F i_{\text {pos }}+F i_{\text {neg }}\right) .
$$

The index $k_{p i}$ characterises the weighting of the difference among the complete group of verbal units. The higher is the positive (or negative) directedness of the evaluations, the closer will be the value $F i$ to the mean value of occurrence of the verbal units of the given group. If, for example, an object ' $i$ ' was perceived as 'pleasant' 5 times and as 'unpleasant' 10 times, then $k p_{i}=(5-10) /(5+10)=-1 / 3$. Then the availability of property 'pleasant' is estimated as follows: $F i_{\text {(pleasant) }}=|-1 / 3| *(5-10)=-5 / 3$ (that is $5 / 3$ times as 'unpleasant').

The computation was performed both across the complete group of test stimuli and for each of them individually. So, we can compare the values of $F i$ corresponding to different groups of verbal units and create the 'verbal portrait' of a sound containing their most subjective significant characteristics.

\subsection{Results}

\subsubsection{Correlation between emotive attributes and preferences}

First, we calculated the general preference expressed by subjects in comparing the noises. The preference $P_{i}$ ( $i$ denoting one of the seven sets of stimuli) is defined as:

$$
P_{i}=\frac{n_{i}}{n_{\text {pres }} * n_{s}}
$$

where

$n_{\text {pres }} \quad$ number of presentations of the noise $i$ (in our case, $n_{\text {pres }}=6$ )

$n_{i} \quad$ number of cases where the noise $i$ is preferred

$n_{s} \quad$ number of subjects in analysed group.

These preference values can be used to estimate the preference probabilities within pairs, using the relation $P_{i j}=P_{i}-P_{j}$. The agreement between these estimated preference probabilities and the real ones was quite good (in each case, the correlation coefficient between the two sets of values was greater than 0.93 ). This proves that the preference values can be represented on an interval scale using the above equation.

Then, we calculated the index $F_{i}$ of emotive attributes' presence in verbalisations produced by all 72 subjects. The result is shown in Figure 1.

The emotive responses were found to be highly correlated with the average of preferences $(R=0.98)$. The differences in the use of emotive attributes to describe the different noises were shown. According to the all pairwise multiple comparison procedure, most of the noises were perceived as different $(p<0.001$, Kruskal-Wallis one way analysis of variance on ranks), except the three pairs (car 1 vs. car 4, car 1 vs. car 6 , car 4 vs. car 6) which contained the sounds perceived as similar ones. The result concerning the high similarity of the given sounds well corresponded with the one related to the subjective evaluation of their difference: the smallest values of subjective differences were revealed for the same three pairs: 3.35 for the pair $1-4,3.57$ for the pair $1-6$, and 3.55 for the pair 4-6. On the contrary, the biggest value of subjective evaluation of difference is given for the pairs being the most 'far' in terms of preference and emotional attitude: 6.21 for the pair 5-7, and 5.60 for the pair 3-5. 
Figure 1 Relative presence of emotive attributes and preferences of noises

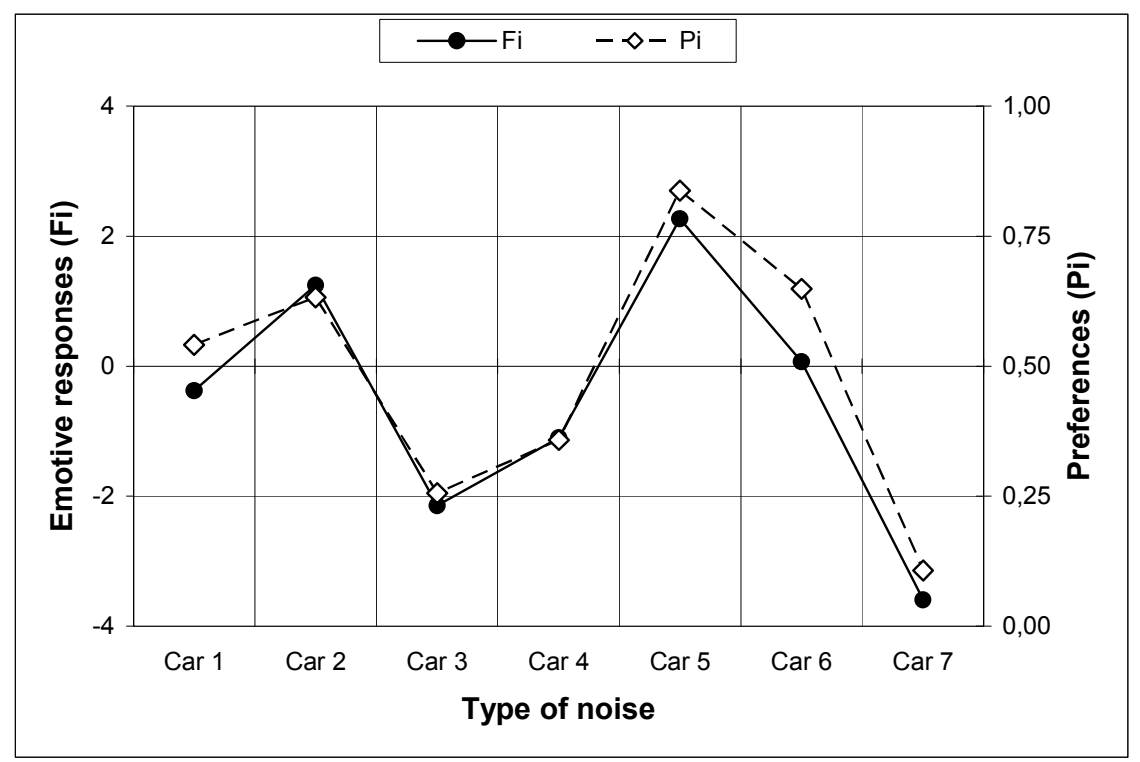

In accordance with these data, we can distinguish a 'very good' noise (car 5) and two 'very bad' ones (cars 3 and 7).

Here are examples of the positive attributes given for the car 5 (223 verbal units): 'more reassuring', 'less tiring', 'certainly nice', 'not aggressive to the ear', 'less troublesome', 'less dirty', 'more security', 'much less violent', 'less hard to bear', 'not catastrophic', etc. The negative attributes concerning the car 5 (28 verbal units) were like the following ones: 'too oppressive', 'not very nice', 'not great', 'not a sweet song', etc.

Positive attributes concerning the car 3 ( 53 verbal units) were like the following ones: 'acceptable, not too', 'nice', 'not bad', 'going better', etc. The examples of negative attributes concerning the car 3 (233 verbal units) are as following: 'more embarrassing', 'it seems that the engine will stall', 'much more uncomfortable', 'disaster', 'a horror', 'the crack is much more unpleasant', 'very aggressive', 'not very satisfactory', 'certainly more annoying in the long', 'more deafening', 'discomfort just ears', 'want to cover the ears', 'the worst', etc.

Let us consider the content of verbalisations produced by subjects when perceiving the noises of the 'good' and 'bad' cars. The examples of verbal portraits created for the noises produced by the cars 3 and 5 are given on the Figure 2.

The verbal portraits show the distribution of different attributes identified by a certain group of subjects as the essential peculiarities of the certain sound. Only those values of $F i$ for which the difference between the relative amount of positively ('Filtered') and negatively ('Not filtered') oriented judgements was significantly different from 0 $(p<0.05)$ are given. The group called 'Others' contains those attributes the relative amount of which is less than $5 \%$. 
Figure 2 'Verbal portraits' for noises of the cars 5 ('good') and 3 ('bad')

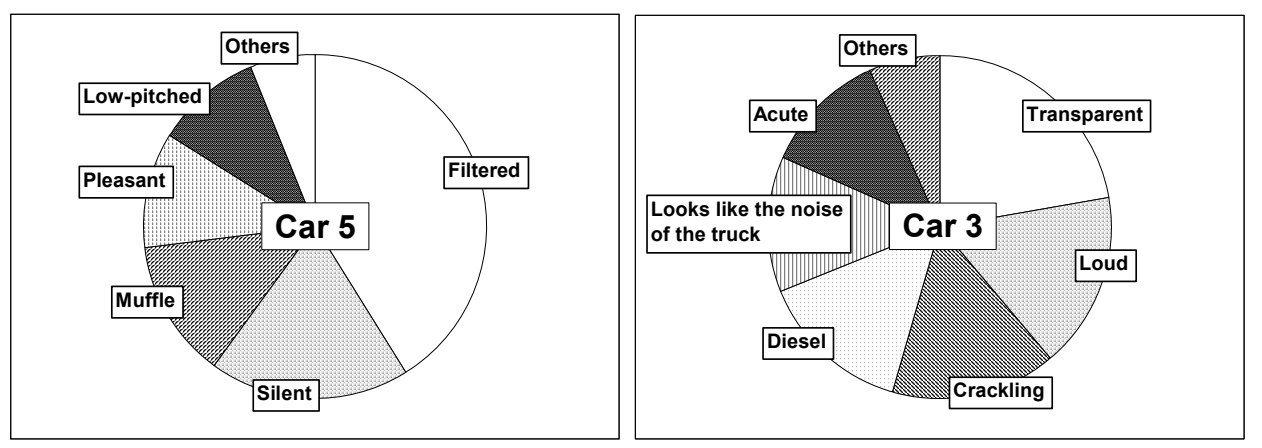

For example, out of 10,796 verbal units, 1,513 characterise the car 5 and contain 304 units representing the emotive attributes (they are grouped here in the category 'pleasant-unpleasant'). Out of 304 verbal units, 256 were positively oriented ('pleasant') and 48 negatively oriented ('unpleasant'). These data was used to calculate the values of $F i$ for emotive attributes present in descriptions of the car 5: $F 5_{\text {pleasant }}=140$. In a similar way, the values of $F 5_{\text {filtered }}, F 5_{\text {silent }}, F 5_{\text {muffle }}$, etc., were calculated. The calculations were made separately for each sound and each group of participants.

The verbal portraits show the relative proportion of $F i$ calculated for each category of judgements in the whole set of descriptions. As it is shown on the Figure 2, the verbal portrait of the noise produced by the car 3 does not contain the category of the emotive attributes while in the portrait created for the car 5 the category 'pleasant' has $11 \%$ of the whole number of verbal attributes.

\subsubsection{Relationship of listening experience with emotive responses of subjects}

Comparing of data concerning verbalisations, produced by 'professional' and 'naive' subjects has shown no differences in the use of emotive attributes (see Figure 3).

'Naive' as compared to 'professional' subjects seem to better differentiate the 'good' (car 5) and the 'bad' (car 3) noises, giving them correspondingly more positive and negative emotive attributes. But this differentiation is not significant. It should be noted that the analysis of the preferences given by these two groups of subjects also did not reveal significant differences (Nosulenko et al., 2000).

Analysis of data concerning the noise preferences given by the seven groups of subjects differentiated by the experience of driving a certain type of a car showed no peculiarities in comparison with the general tendencies revealed for the whole sample of subjects. However, the peculiarities in emotional evaluations were revealed for some of those groups. The most vivid results were revealed for the verbal data obtained from the subjects having experience in driving the car 3 (see Figure 4). The subjects having an experience in driving this 'bad' car showed much more critique towards its noise $\left(F 3_{\text {Drivers } 3}=-4.123 ; F 3_{\text {Others }}=-1.825 ; t=-2.908 ; p=0.005\right)$ and gave significantly more positive evaluations of 'good' (car 5) noise in comparison with the subjects lacking this experience $\left(F 5_{\text {Drivers } 3}=3.608 ; F 5_{\text {Others }}=2.049 ; t=2.160 ; p=0.034\right)$. 
Figure 3 Relative presence $(F i)$ of emotive attributes in verbalisations produced by 'professional' and 'naive' subjects

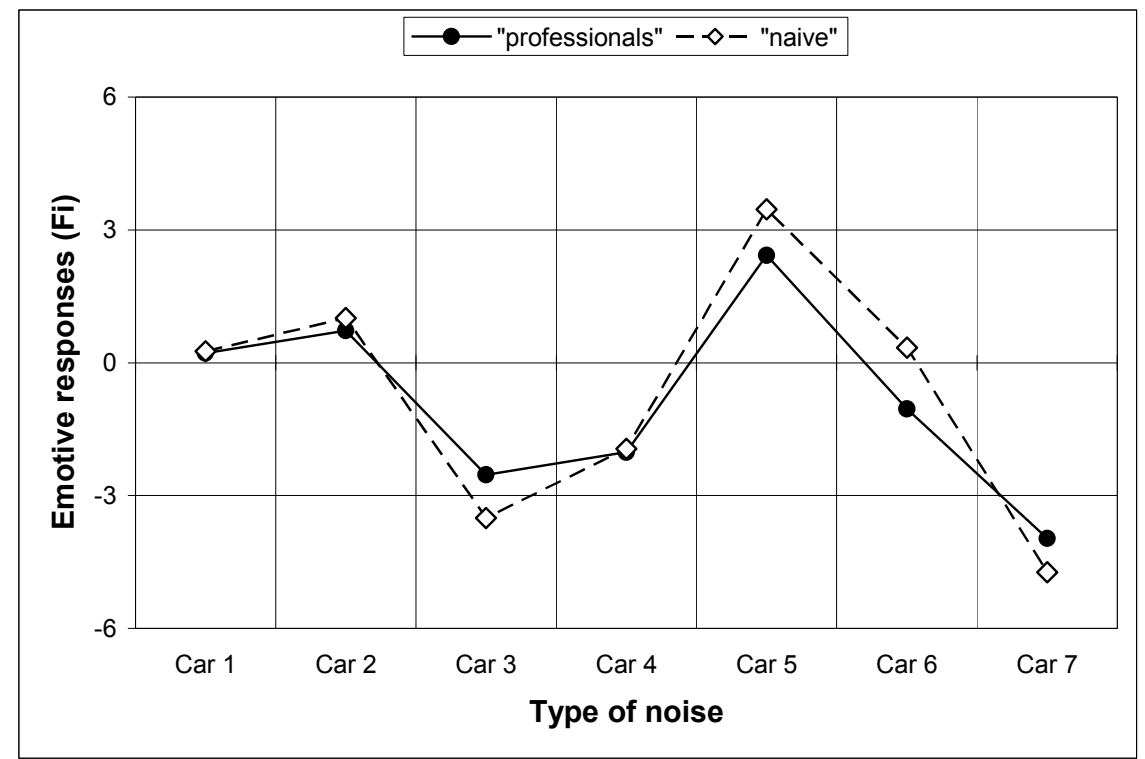

Figure 4 Relative presence $(F i)$ of emotive attributes in verbalisations produced by subjects drivers of the car 3 (seven males, two females)

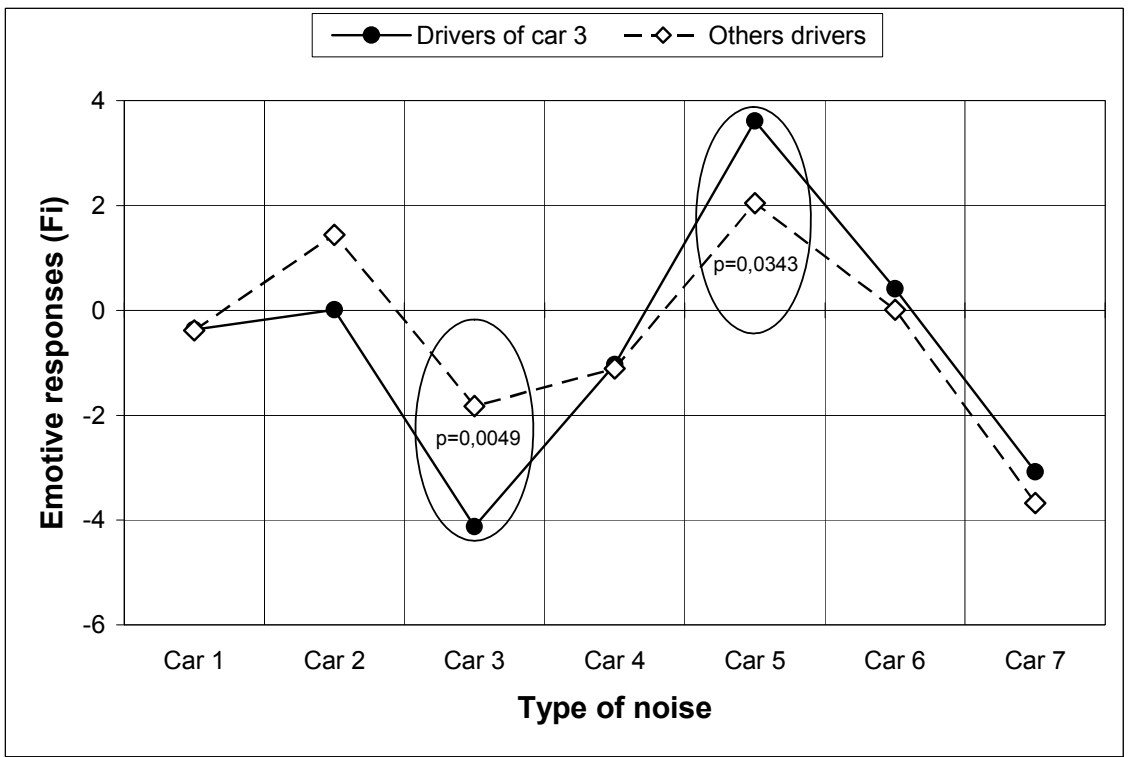

The same tendency was revealed for the emotional attributes given by subjects having experience in driving the 'bad' car 7. These subjects evaluated it less positively in comparison with the 'good' one (car 5). 
At the same time, the subjects having experience in driving the 'good' car 5 did not differentiate it among the other cars in terms of emotional evaluations. As for the subjects having experience in driving the other cars, the distribution of emotive attributes they gave was the same as the one revealed for the whole sample of subjects.

Although the statistically significant differences in emotional evaluations given for 'good' and 'bad' cars were shown only for the subjects having experience in driving the car 3, it seems reasonable to conclude that there is a relationship between those evaluations and experience of driving a certain car.

As a result, the analysis of content of verbalisations produced by the given groups of subjects shows unequal weight of different attributes in verbal portraits and namely of the significant presence of the emotional ones (see Figure 5).

On the Figure 5, two verbal portraits are presented. The first one was created for the noise of the car 3 from the verbal descriptions given by the subjects having experience in driving this car. The second one represents the portrait based on the descriptions given by other groups of drivers. Comparison of the two verbal portraits shows a considerable presence of the category 'unpleasant' $(20 \%)$ in the one related to the descriptions made by the drivers of the car 3 and the absence of this category in the portrait related to the whole sample of drivers. The difference in the portraits also concerns the relative weight of the category 'Loud'. For the drivers of the car 3 this category is not pertinent (verbal portrait does not contain this category), but for others drivers this category is very present $(17 \%)$.

Figure 5 'Verbal portraits' for the noises of the car 3 perceived by drivers of this car in comparison with others subjects
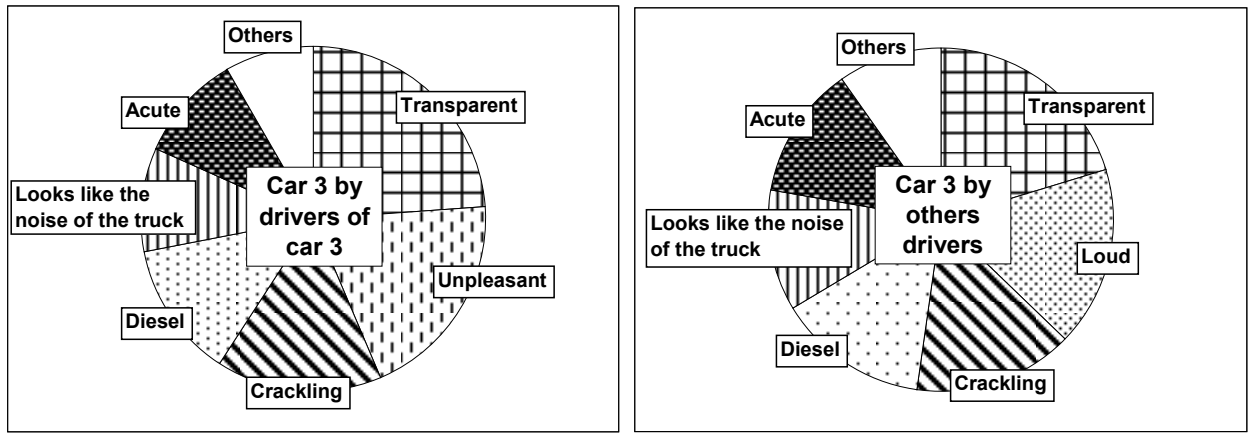

\subsubsection{Gender differences in use of emotive features}

As it was shown in our previous study (Nosulenko et al., 2000), no significant differences in noise preferences made by males and females were revealed while the significant differences in verbalisations were shown: in comparison with females, males used in general more details to describe the noises.

On the Figure 6, the relative presence of emotive attributes in verbalisations produced by males and females is presented. 
Figure 6 Relative presence (Fi) of emotive attributes in verbalisations of subjects - females and subjects - males

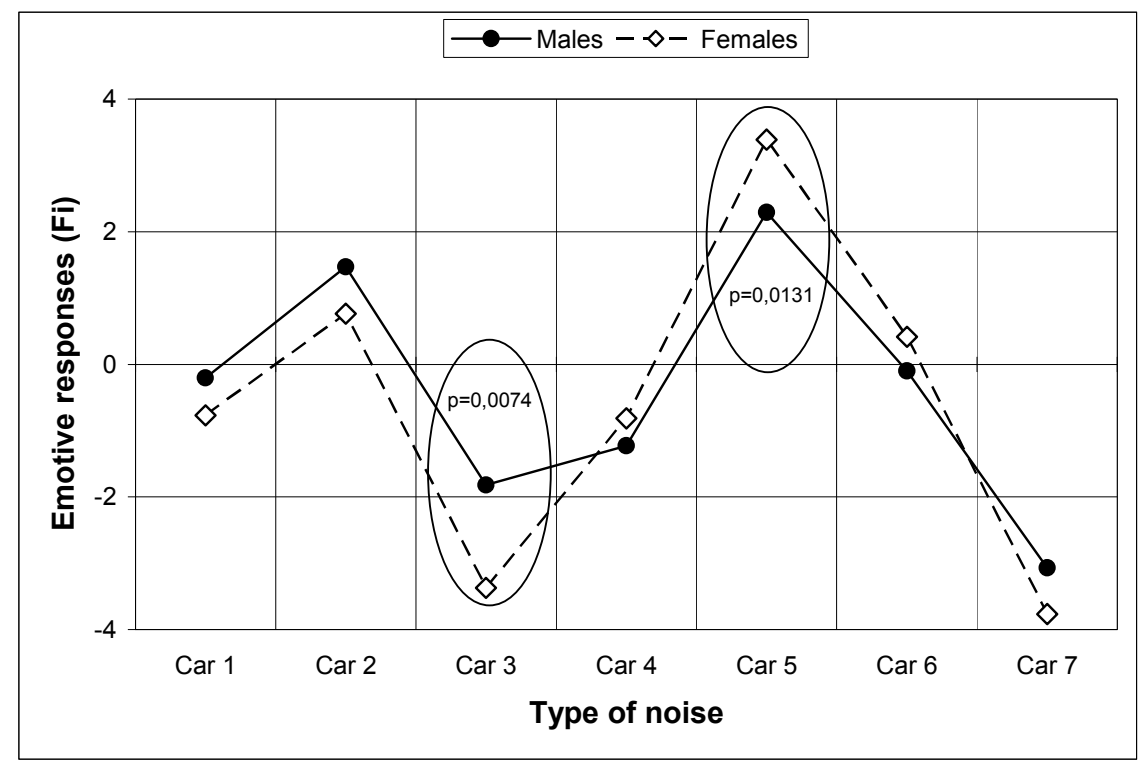

There is a tendency for females in comparison with males to give more negative evaluations when describing a bad car and more positive evaluations for the 'good' car. The most evident differences are revealed in descriptions related to the 'bad' car 3 $\left(F 3_{\text {Males }}=-1.821 ; F 3_{\text {Females }}=-3.373 ; t=2.763 ; p=0.007\right)$ and the 'good' car 5 $\left(F 5_{\text {Males }}=2.291 ; F 5_{\text {Females }}=3.388 ; t=-2.548 ; p=0.013\right)$. Thus, the analysis of verbal data obtained in the course of comparison of acoustical objects demonstrated also gender differences in emotional evaluations.

\section{Conclusions}

The analysis showed that emotive attributes used to describe the compared noises constitute around $19 \%$ of the total volume of verbalisations. Emotional components identified in the perceived quality contain a rich set of features which characterise in details the general impressions from the sounds as well as their similarities and differences. A high correlation between the frequencies of use of emotive attributes and noise preferences was shown.

On the basis of quantitative presence of emotive attributes in verbal portraits created for compared noises, the differentiation of noises identified as 'good' and 'bad' was done. Also, subjects having different experience of listening to these noises were shown to have different quantity of emotive attributes.

We can also state that in a number of cases an analysis of free verbalisations can give more information than psychophysical data on preferences. In the given study, it could be demonstrated by the fact that the analysis of quantitative presence of emotive evaluations gives a possibility to reveal peculiarities in perception of noise which are specific to 
people having different experience of listening to it: the drivers of a car producing this noise and the drivers lacking this experience.

The most significant results concern the cases when the most negative and the most positive emotive evaluations were given: the drivers having an experience in driving the car which noise was identified as 'bad' give more negative evaluations to it than other drivers. On the contrary, the car having a 'good' noise receives from this driver significantly more positive evaluations than from the other groups of drivers.

In addition, the emotive evaluations' analysis shows differences in perception of noises by males and females. The gender differences manifest themselves in a following way: women give more negative emotive evaluations than men to the car identified as 'bad', and more positive emotive evaluations to the car identified as 'good'. However, no significant differences in the frequency of emotive attributes given by people having experience in acoustical evaluation and those ones lacking this experience were revealed. It should be mentioned that significant differences between these groups of subjects were not revealed as well in the previous analysis of preferences.

The results obtained in this study support the previous conclusions we have made about the free verbalisations as a very useful source of information concerning perception (Nosulenko et al., 1998; Parizet et al., 2007). In the course of these verbalisations, a special place should be attributed to the objects' comparison - an important condition of receiving a rich and significant data (Nosulenko and Samoylenko, 1997, 2001, 2009; Samoylenko et al., 1996).

The verbal protocol analysis realised in that study can now be used by the supplier to evaluate the influence of noises produced by car engines and to identify the part of emotive attributes in the perceived quality of noises. The verbal portraits created on the basis of this analysis give a possibility to interpret the cars' preferences made by customers and to define the strategies of improvement of the cars. The detailed illustrations of applications of our approach to resolution of concrete tasks are presented in the book (Lahlou et al., 2012) as well as in the works of other researchers who use the given method (Clouet, 2005; Geissner, 2006; Le Bellu, 2011; Montignies, 2009).

\section{Acknowledgements}

This research was supported by the Russian Human Sciences Foundation, Grant No. 11-06-01176a.

\section{References}

Berg, J. and Rumsey, F. (2000) 'Correlation between emotive, descriptive and naturalness attributes in subjective data relating to spatial sound reproduction', 109th AES Convention, Los Angeles.

Bradley, M.M. and Lang, P.J. (2000) 'Affective reactions to acoustic stimuli', Psychophysiology, Vol. 37, No. 2, pp.204-215.

Clouet, G. (2005) Evaluation ergonomique de produits et services: le cas du web marchand, $\mathrm{PhD}$ thesis, Université Paris-8, Saint-Denis, France.

Faure, A., McAdams, S. and Nosulenko, V. (1996) 'Verbal correlates of perceptual dimensions of timbre', Proceedings of the Fourth International Conference on Music Perception and Cognition, pp.79-84, Montréal, McGill University. 
Geissner, E. (2006) Perception du bruit extérieur d'un véhicule urbain de livraison, $\mathrm{PhD}$ thesis, Institut National des Sciences Appliquées de Lyon, Lyon, France.

Lahlou, S., Nosulenko, V. and Samoylenko, E. (2012) Numériser le travail. Théories, méthodes, experimentations, Edition 'Lavoisier', Paris.

Le Bellu, S. (2011) Capitalisation des savoir-faire et des gestes professionnels dans le milieu industriel, $\mathrm{PhD}$ thesis, Université Bordeaux Segalen, Bordeaux, France.

Montignies, F. (2009) La perception sonore dans un processus de conception centrée sur l'homme. Application aux bruits de tapotements de planches de bord automobiles par les clients, $\mathrm{PhD}$ thesis, Institut National des Sciences Appliquées de Lyon, Lyon, France.

Montignies, F., Nosulenko, V. and Parizet, E. (2010) 'Empirical identification of perceptual criteria for customer-centred design: focus on the sound of tapping on the dashboard when exploring a car', International Journal of Industrial Ergonomics, Vol. 40, No. 5, pp.592-603.

Nosulenko, V. (2008) 'Mesurer les activités numérisées par leur qualité perçue', Social Science Information, Vol. 47, No. 3, pp.391-417.

Nosulenko, V. and Samoylenko, E. (1997) 'Approche systémique de l'analyse des verbalisations dans le cadre de l'étude des processus perceptifs et cognitifs', Social Science Information, Vol. 36, No. 2, pp.223-261.

Nosulenko, V. and Samoylenko, E. (2001) 'Evaluation de la qualité perçue des produits et services: approche interdisciplinaire', International Journal of Design and Innovation Research, Vol. 2 , No. 2, pp.35-60.

Nosulenko, V. and Samoylenko, E. (2009) 'Psychological methods for the study of augmented environments', in Lahlou, S. (Ed.): Designing User Friendly Augmented Work Environments, pp. 213-236, Springer Verlag, London.

Nosulenko, V., Parizet, E. and Samoylenko, E. (1998) 'La méthode d'analyse des verbalisations libres: une application à la caractérisation des bruits de véhicules', Social Science Information, Vol. 37, No. 4, pp.593-611.

Nosulenko, V., Parizet, E. and Samoylenko, E. (2000) 'Différences individuelles de perception de bruits de véhicules à moteur diesel', Revue française de marketing, Vols. 4-5, Nos. 179/180, pp.157-165.

Parizet, E. and Nosulenko, V. (1999) 'Multi-dimensional listening test: Selection of sound descriptors and design of the experiment', Noise Control Engineering Journal, Vol. 47, No. 6, pp.227-232.

Parizet, E., Amari, M. and Nosulenko, V. (2007) 'Vibro-acoustical comfort in cars at idle: human perception of simulated sounds and vibrations from 3- and 4-cylinder diesel engines', International Journal of Vehicle Noise and Vibration, Vol. 2, No. 2, pp.143-156.

Parizet, E., Guyader, E. and Nosulenko, V. (2008) 'Analysis of car door closing sound quality', Applied Acoustics, Vol. 69, No. 1, pp.12-22.

Parker, S., Bascom, J., Rabinovitz, B. and Zellner, D. (2008) 'Positive and negative hedonic contrast with musical stimuli', Psychology of Aesthetics, Creativity, and the Arts, Vol. 2, No. 3, pp.171-174.

Ross, R. (1939) 'Optimal orders in the method of paired comparisons', Journal of Experimental Psychology, Vol. 25, No. 4, pp.417-421.

Samoylenko, E. and McAdams, S. et al. (1996) 'Systematic analysis of verbalizations produced in comparing musical timbres', International Journal of Psychology, Vol. 31, No. 6, pp.255-278.

Scherer, K.R. (2005) 'What are emotions? And how can they be measured?', Social Science Information, Vol. 44, No. 4, pp.695-729.

Västfjäll, D., Gulbol, M-A., Kleiner, M. and Gärling, T. (2002) 'Affective evaluations of and reactions to exterior and interior vehicle auditory quality', Journal of Sound and Vibrations, Vol. 255, No. 3, pp.501-518. 